\title{
Auxiliary chemical therapies in the treatment of aggressive periodontitis: current aspects
}

\author{
Terapias químicas auxiliares para o tratamento da periodontite agressiva: aspectos atuais
}

\author{
Lauro Garrastazu AYUB' \\ Arthur Belém NOVAES JÚNIOR ${ }^{1}$ \\ Márcio Fernando de Moraes GRISI' \\ Sérgio Luís Scombatti de SOUZA' \\ Daniela Bazan PALIOTO' \\ Mário TABA JÚNIOR ${ }^{1}$
}

\begin{abstract}
Aggressive periodontitis, a distinct clinical entity of periodontal disease, is characterized by a pronounced episodic and rapid destruction of periodontal tissues and may result in rapid and early loss of teeth. Some studies have shown that conventional mechanical debridement together with oral hygiene is often not sufficient to disease control. Recent studies of this condition have shown beneficial effects of auxiliary therapies or adjuncts such as the administration of systemic and locally antimicrobials. Among the local adjuncts, the literature presents antiseptics, antibiotics and photodynamic therapy. Antibiotics and anti-inflammatory represent systemic adjuncts. Regardless of the results presented by each of them, the difficulty of establishing a single protocol for all cases is recognized depending on the individual response shown by each patient. The aim of the present study was to review the current results about chemical adjuncts administration associated with conventional treatment in cases of aggressive periodontitis and suggest clinical protocols.
\end{abstract}

Indexing terms: Aggressive periodontitis. Anti-bacterial agents. Anti-infective agents, local. Anti-inflammatory agentes. Mouthwashes. Photochemotherapy.

\section{RESUMO}

A periodontite agressiva, uma entidade clínica distinta da doença periodontal, é caracterizada por uma pronunciada destruição episódica e rápida dos tecidos periodontais e pode resultar em perda rápida e precoce dos dentes. Alguns trabalhos têm mostrado que o debridamento mecânico convencional juntamente com higiene oral muitas vezes não é suficiente para o controle da doença. Apesar de não existir consenso, estudos recentes desta condição mostram efeitos benéficos de terapias auxiliares ou coadjuvantes como a administração de antimicrobianos sistêmicos e locais. Entre os coadjuvantes locais, a literatura apresenta os antissépticos, antibióticos e terapia fotodinâmica. Dentre os sistêmicos são representados os antibióticos e antiinflamatórios. Independentemente dos resultados apresentados por cada um deles, se reconhece a dificuldade em se estabelecer um protocolo único para todos os casos em função da resposta individual apresentada por cada paciente. O objetivo do presente estudo foi revisar os resultados atuais sobre administração de coadjuvantes químicos associados à terapia convencional em casos de periodontite agressiva e sugerir protocolos clínicos.

Termos de indexação: Periodontite agressiva. Antibacterianos. Anti-infecciosos locais. Antissépticos bucais. Anti-inflamatórios. Fotoquimioterapia.

\section{INTRODUCTION}

Aggressive periodontitis (AP) comprises a group of rapid progressive periodontitis forms, rare character and routinely graves. Although it can affect any age, often its clinical manifestation occurs ata $n$ early age and it has a distinct tendency to develop in the same family. In 1999, a consensus on the conditions and periodontal diseases was established for an World Workshop of the American Academy of Periodontology. In the absence of an etiological classification, the aggressive forms of periodontal disease were defined on the basis of the following main features ${ }^{1}$ : a) non-significant medical history; b) rapid attachment loss and alveolar bone destruction and c) family concentration of cases.

The diagnosis of AP requires the exclusion of systemic diseases that may harm the host defense and lead to premature teeth loss (periodontal manifestations of systemic diseases).

The existence of particular forms of AP was also recognized based on specific clinical and lab characteristics: localized aggressive periodontitis (LAP) and generalized aggresssive periodontitis (GAP) ${ }^{2}$.

A successful treatment of AP is dependent of early diagnosis, directing the therapy to the elimination or deletion of pathogens, providing a favorable

\footnotetext{
${ }^{1}$ Universidade de São Paulo, Faculdade de Odontologia, Departamento de Cirurgia e Traumatologia Buco Maxilo Facial e Periodontia. Av. do Café s/n., 14040-904, Ribeirão Preto, SP, Brasil. Correspondência para / Correspondence to: LG AYUB. E-mail: <lauroayub@hotmail.com>.
} 
environment in the long term. The differential element of AP treatment, however, refers to specific efforts to affect the composition and not only the quantity of the subgingival microbiota.

Despite this, the conventional treatment (scaling and root planning) of the AP remains seen of nonspecific way, with the goal of reducing the bacteria number and, therewith, change the micro environmental conditions of these sites. This nonspecific therapy have been shown to be effective in long term since these patients acquire good oral hygiene habits and are inserted into supportive periodontal therapy (SPT) programs. However, a small but relevant site or patient groups, does not respond appropriately to this treatment type ${ }^{3}$. Different factors have been proposed in an attempt to explain the lack of response from that group of patients to conventional treatment ${ }^{4}$, being one of the most investigated, the periodontal pathogens persistence in affected sites ${ }^{5}$.

Based on these considerations, of which only the mechanical treatment (conventional) may not be effective for certain sites or patients, additional antimicrobial therapies have been reported in an attempt to improve clinical outcomes. Chemical auxiliaries so would present a significant relevance to the success in the treatment of certain cases of $\mathrm{AP}^{6}$. However, the identification of these patients is not simple, since the professional should be aware of possible failures caused by his limited experience with regard to conventional therapy and the lack of collaboration/patient compliance to treatment.

The literature has presented many protocols of periodontal diseases treatment, including chemical adjunctive with conventional therapy (for review ${ }^{7-9}$ ). The $\mathrm{AP}$, as known, evolves rapidly both by high pathogenicity present biofilm, as by deficient host response ${ }^{10}$. Figure $1^{11}$ represents the interrelation between the host response and microbial challenge and its influences in the onset and progression of periodontal disease. Facing this situation, the professional search a therapy to stop as soon as possible the increasing clinical attachment loss by these patients, keeping in mind that a "sub-intervention" could lead to progression and/or worsening of cases.

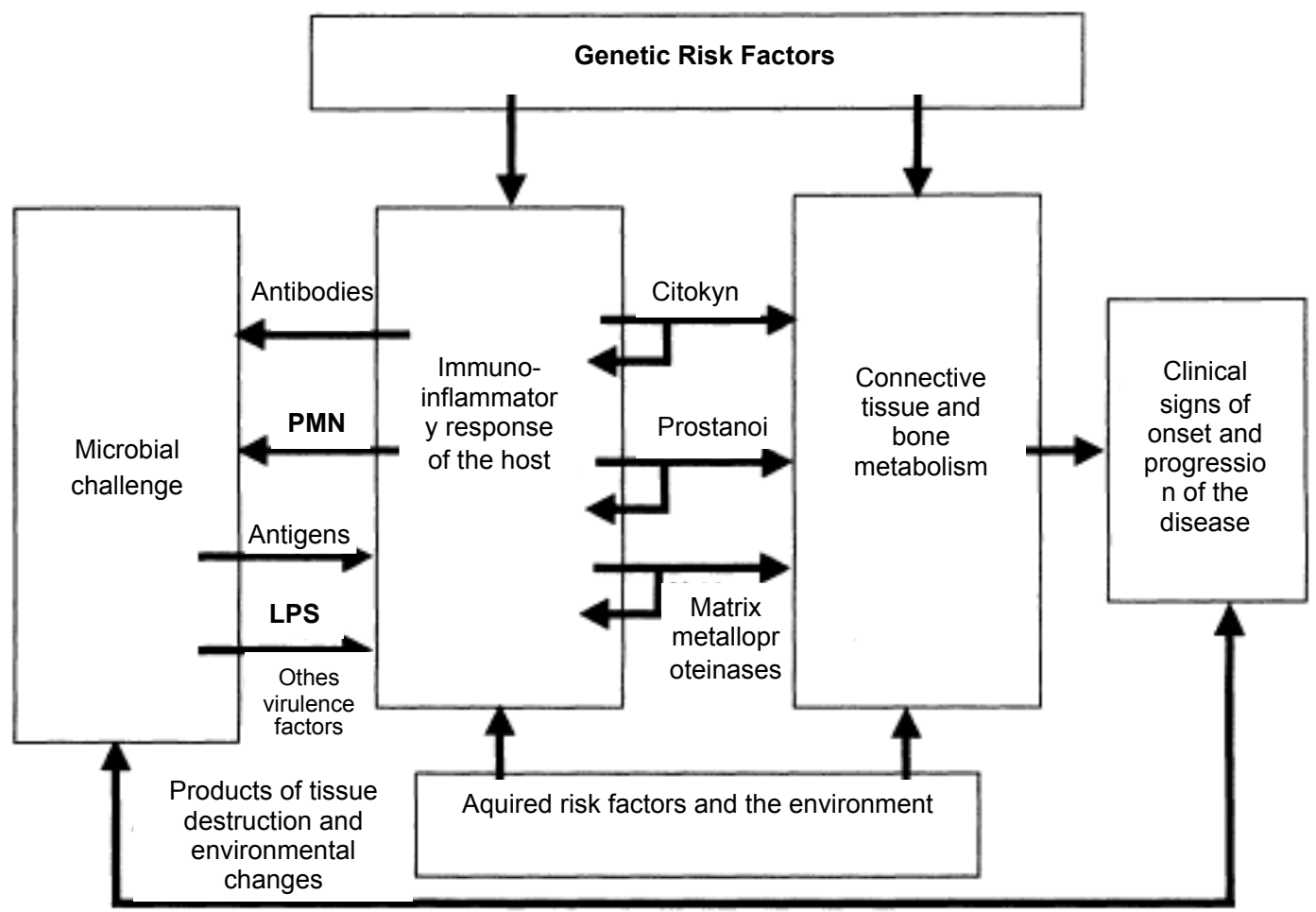

Figure 1. Biological mechanisms of periodontal disease.

Legend: PMN = polymorphonuclear; LPS = lipopolysaccharides.

Source: adapted from Kornman ${ }^{11}$. 
For that, the use of an antimicrobial should be considered when the professional is facing many severe episodes. The interruption of disease course and the conservation of clinical results achieved should be the focus of the periodontist.

Therefore, the study purpose is to review the options presented in the literature regarding treatment protocols of the AP that include chemical adjuncts. In addition, demonstrate which antimicrobials present better results, when associated with conventional therapy, taking into consideration their clinical implications and the overall health of patients.

\section{Use of chemical adjuncts}

The chemical adjuncts shown in the literature for the AP treatment can be didactically divided in: local and systemic.

\section{Local}

The biggest challenge for local antimicrobials agents is the maintenance of therapeutic levels in subgingival region for a suitable period of time.

\section{Antiseptics}

Several antiseptics have been tested for inhibiting biofilm formation and most have shown little or no effect on formed biofilm or installed disease. Because of this, these agents act normally more in a preventive than therapeutic way. The antiseptic that present good clinical results are able to inhibit the development of biofilm and consequently prevent the occurrence of gingivitis. The literature mentions multiple agents with antimicrobial action and some vehicles for administration of these agents (for review ${ }^{12-13}$ ), being the majority information related to mouthwash and toothpastes.

Among the antiseptics associated with the treatment of AP, chlorhexidine (bisbiguanide antiseptic) is certainly the most studied, although it is also associated with the immediate maintenance of results achieved with conventional therapy (preventive effect).

\section{Chlorhexidine}

Chlorhexidine, despite some side effects, timedependent and concentration used, perhaps represents the only chemical agent employed as a substitute, not a helper, for mechanical oral hygiene practices to patients with healthy periodontium ${ }^{14}$. Information about the toxicology of chlorhexidine confirms its safety for intraoral use and demonstrates its important antimicrobial effect on Gram-positive and Gram-negative bacterias ${ }^{15}$.

\section{Clinical presentations}

Despite having been developed several products with chlorhexidine as active ingredient (mouthwash, gels, sprays, toothpasts and varnishes), the solutions and the soft arrays (chip) for subgingival application that received greater attention in the AP treatment.

The idea of irrigating the periodontal pocket with chlorhexidine solutions ( 0.12 or $0.2 \%$ ) was tested by the researchers to achieve therapeutic levels in the environment. Some have adopted the subgingival irrigation through a syringe as an adjunct to treatment convencional ${ }^{16-20}$, while others evaluated the effect of chlorhexidine as part of ultrasonic instrumentation ${ }^{21-22}$. None of these studies found additional clinical effects the use of chlorhexidine as solution, when compared to treatment with manual scaling and root planning or with ultrasonic device (using water as solution).

In some single-stage protocols for the treatment of $\mathrm{AP}$, chlorhexidine (solution, spray and gel) is indicated as an adjunct efficient, being associated with better clinical microbiologic outcomes ${ }^{23-25}$. However, in recent years, was published a systematic review that assessed the effects of debridement in single-stage (with or without antiseptic) and conventional therapy in patients with chronic periodontitis. This study did not find a relevant clinical advantage among the protocolos ${ }^{26}$.

Other clinical presentation widely investigated is the chip with chlorhexidine gluconate $(2.5 \mathrm{mg})$. In a multi-center study, Soskolne et al. ${ }^{27}$, found a statistically significant reduction in the clinical attachment level (CAL) in the group treated with chlorhexidine chip and scaling and root planning (SRP) compared to the control group (only SRP) at 6 months of follow-up. Jeffcoat et al. ${ }^{28}$ conducted a multi-center randomized controlled study where they suggested the use of chlorhexidine chip as safe and effective for the treatment of chronic periodontitis. Another study evaluated the efficacy of chlorhexidine associated with chip SRP compared to treatment with SRP. The authors reported a significant reduction in levels of matrix metalloproteinase-8 (MMP8) in gingival crevicular fluid of the test group (SRP + chip) for a period of 6 months and have not found differences when analyzed the clinical parameters ${ }^{29}$. However, Duarte et al. analyzed the additional effect of chlorhexidine chip to conventional treatment (SRP). The 
study showed that the adjuvant was unable to promote improvement in clinical and microbiological parameters, when compared to the SRP after 9-month follow-up ${ }^{30}$. Recently, another study found better clinical results with the use of chlorhexidine chip associated with SRP (reduction in probing depth (PD) and gain in $\mathrm{CAL}$ ) in patients with $\mathrm{PA}^{30}$.

\section{Antibiotics}

Although there are a large number of antibiotics, few of these drugs are used for local application. These antimicrobials may be rapidly diluted by gingival crevicular fluid greatly affecting his performance within the periodontal pocket, this being the greatest challenge for local agents.

The Chart 1 mentions clinical presentations of different antibiotics used in the treatment of chronic periodontitis, in recurrent sites to conventional therapy or SPT fase, since these can target research with AP:

Chart 1. Antibiotics administered locally.

\begin{tabular}{|lc|}
\hline Agent & Vehicle / Formulation \\
\hline Tetracycline & fiber $25 \%$ \\
Metronidazole & gel $25 \%$ \\
Doxycycline & biodegradable matrix $8.5 \%$ \\
Doxycycline & biodegradable gel $15 \%$ \\
Minocycline & gel or ointment $2 \%$ \\
Minocycline & microcapsules \\
& gel (metronidazole) $25 \% \times$ ointment \\
(tetracycline) $3 \%$ \\
Comparison & ointment (minocycline) $2 \% \times$ \\
& fiber (tetracycline) $25 \% \times$ gel \\
(metronidazole) $25 \%$
\end{tabular}

Source: Adapted from Hanes \& Purvis?

The authors of this review concluded that the Minocycline (gel and microcapsules) and Doxycycline (gel) were the agents that provided an added benefit to clinical parameters (PD and $\mathrm{CAL}$ ) in the treatment of periodontal disease.

A few researchers analyzed the use of these agents in the treatment of AP. In 2006, Ağan et al. ${ }^{31}$ published a pilot study where they analyzed the effect of doxycycline gel application (10\%) in levels of MMP-8 in patients with chronic and aggressive periodontitis. The authors found no significant difference between the groups (only SRP and doxycycline gel + SRP).

\section{Photodynamic therapy}

Photodynamic therapy (PDT) is based on the activation principle of a substance (dye) activated by a light source with a wavelength $(\lambda)$ suitable. The photomodifications that occurred in this dye will produce singlet oxygen and free radicals, substances that are cytotoxic to bacteria. PDT's ability to induce the death of periodontium pathogens has been demonstrated in studies with animals ${ }^{32}$.

In recent years, two studies have examined the effect of PDT in the treatment of patients with AP. In the first study, de Oliveira et al. found clinical outcomes similar to SRP and PDT in PD sites $\geq 5 \mathrm{~mm}$ after 3 months of follow-up ${ }^{33}$. The tumor necrosis factor (TNF- $\alpha$ ) and the ligand receptor activator of nuclear factor kappa B (RANKL) are cytokines related to connective tissue and bone destruction. Preliminary results of these cytokines levels in gingival crevicular fluid of patients with PA were similar when compared SRP and PDT ${ }^{34}$. Despite this, the researchers warn of the need for more studies to prove these results. Azarpazhooh et al. ${ }^{35}$ published a systematic review and meta-analysis where articles were analyzed for the therapy of chronic and aggressive periodontitis. The PDT as independent or associated with the treatment was not exceeding SRP only.

The Chart 2 summarizes the evidence presented by the literature and suggests clinical protocols that use locally auxiliary therapy:

Chart 2. Evidence and clinical protocols suggested for local adjuncts.

\begin{tabular}{|llc|}
\hline Therapy & \multicolumn{1}{c}{ Suggested protocol } & $\begin{array}{c}\text { Evidences and } \\
\text { references }\end{array}$ \\
\hline Chlorhexidine & $\begin{array}{l}\text {-Irrigating subgingival } \\
\text { (syringe or ultrasonic } \\
\text { debridement); } \\
\text {-Solution, spray, gel; } \\
\text {-Chip }\end{array}$ & Weak $^{17-31}$ \\
$\begin{array}{l}\text { Doxycycline } \\
\begin{array}{l}\text { Photodynamic } \\
\text { therapy }\end{array}\end{array}$ & $\begin{array}{l}\text {-Gel (10\%) } \\
\text {-Laser dyodo }(\mathbb{m i n})+\text { fenotiazina dye }\end{array}$ & Weak $^{32}$ \\
\hline
\end{tabular}

\section{Systemic}

\section{Antibiotics}

The literature presents numerous studies that describe the effects of systemic antibiotics administration in the treatment of periodontal disease. Unfortunately, the studies have great heterogeneity on 
the type of antibiotic, dosage, duration, tracking time and population analyzed.

In recentyears, were published two systematic reviews that report the benefits of the systemic antibiotics use in the treatment of $A P$, showing better clinical results ( $P D$ reduction and CAL gain) when compared to conventional therapy. In addition, the use of these protocols offers better results in cases of $A P$, in relation to chronic cases ${ }^{8-9}$. Nevertheless, it is still not possible to say what the best antimicrobial agent and treatment protocol that should be recommended. To Herrera et al. ${ }^{9}$, spiramycin and the association between amoxicillin and metronidazole together with SRP, demonstrated a statistically significant benefit in PD reduction and CAL gain in deep pockets, respectively. Haffajee et al. ${ }^{8}$, found a significant CAL gain in the cases treated with tetracycline and metronidazole. In addition, the initial data of amoxicillin + metronidazole have shown positive clinical effects.

The use of amoxicillin + metronidazole as an adjunct to the non-surgical therapy (single-stage) showed superior clinical results to the conventional treatment in patients with generalized AP after 6 months followup (short-term) ${ }^{36}$. Another point in the studies analyzed concerns the changes in microbiological profile provided by amoxicillin + metronidazole. Valenza et al. ${ }^{37}$ found no change in the subgingival microbiota of patients with $A P$ after 12 months, however, most of the studies relates a favorable change in the microbiological profile of patients who use these antimicrobial association ${ }^{38-39}$. In addition, all report favorable clinical results (no control group) or better than conventional treatment ${ }^{38-39}$. When this association (amoxicillin + metronidazole) was compared with another protocol (doxycycline), both provided improvement in clinical and microbiological parameters in 3 months follow-up ${ }^{40}$.

Other protocols have also been tested and compared with each other. The association of amoxicillin and metronidazole or metronidazole only provided a beneficial effect on clinical (PD) and microbiological outcomes. Doxycycline, however, failed to demonstrate benefits to conventional therapy in patients with generalized $\mathrm{AP}^{41}$. On the other hand, Machtei et al. ${ }^{42}$ when compared the effect of doxycycline and amoxicillin + metronidazole as adjuncts to the non-surgical therapy, found similar improvements in clinical and immunological parameters evaluated, recommending the use of both antibiotic regimes. Azithromycin is another who presented antimicrobial clinical benefits (PD and CAL) in AP treatment when associated with the SRP for a period of 12 months. In addition, the researchers noted that this is a protocol that requires less time and dosage, which facilitates the patient's collaboration ${ }^{43}$.
Another study evaluated the effect of patients partial adhesion of prescribed antibiotic regime, amoxicillin + metronidazole, in non-surgical AP treatment. Within the limitations of this study design (patients report), the data suggested that incomplete adherence to the prescribed adjunct for 7 days were associated with worse clinical outcomes analyzed (PD and $\mathrm{CAL})^{44}$.

The right moment to indicate the systemic antibiotic was also evaluated in patients with AP. Kaner et al. ${ }^{45}$ analyzed the effect amoxicillin + metronidazole immediately after SRP or 3 months after initial therapy (including subgingival reinstrumentation at this stage for this group). The findings, after 6 months, indicated a further PD reduction and greatest gain in CAL on statistically significant in the group that received antibiotics immediately after SRP.

\section{Anti-inflammatory}

A pilot study published in recent years evaluated the effect of anti-inflammatory drug etoricoxib as adjuvant to SRP in AP treatment. The etoricoxib was unable to promote additional benefits to clinical parameters when compared to conventional treatment ${ }^{46}$

Another study has demonstrated clinical benefit (PD reduction in deep pockets) when loxoprofen was associated with SRP in patients with periodontal disease, not being specified the subtype disease ${ }^{47}$.

The Chart 3 summarizes the evidence presented by the literature and suggests clinical protocols that use auxiliary systemic therapies:

Chart 3. Evidence and clinical protocols suggested for systemic adjuncts

\begin{tabular}{|c|c|c|}
\hline Therapy & Suggested protocol & $\begin{array}{l}\text { Evidences and } \\
\text { references }\end{array}$ \\
\hline \multicolumn{3}{|l|}{ Antibiotics } \\
\hline Spiramycin & -1,5 UI, 2x/dia, 14 days & Weak $^{11}$ \\
\hline $\begin{array}{l}\text { Amoxicillin + } \\
\text { Metronidazole }\end{array}$ & $\begin{array}{l}-500 m g+500 m g, 3 x / \text { day, } 7 \\
\text { days; } \\
-500 m g+400 m g, 3 x / \text { day, } 14 \\
\text { dias }\end{array}$ & Strong $10,11,37-43$ \\
\hline Doxycycline & $\begin{array}{l}-200 \mathrm{mg}\left(1^{\circ} \text { dosage }\right) \text { and } \\
100 \mathrm{mg}{ }_{1} \\
1 \mathrm{x} / \mathrm{dia}^{\prime} 14 \text { days }\end{array}$ & Weak ${ }^{41-43}$ \\
\hline Tetracycline & $-250 \mathrm{mg}, 4 \mathrm{x} /$ day, 14 days & Weak ${ }^{10}$ \\
\hline Metronidazole & $\begin{array}{l}-250 \mathrm{mg}, 3 x / \text { day, } 7 \text { days; } \\
-500 \mathrm{mg}, 3 x / \text { day, } 7 \text { days }\end{array}$ & Weak $^{10,42}$ \\
\hline Azithromycin & $-500 \mathrm{mg}, 1 \mathrm{x} /$ day, 3 days & Moderate $^{44}$ \\
\hline \multicolumn{3}{|c|}{ Anti-inflammatory } \\
\hline Etoricoxib & $-120 \mathrm{mg}, 1 \mathrm{x} /$ day, 7 days & Very weak ${ }^{48}$ \\
\hline Loxoprofen & $-60 \mathrm{mg}, 1 \mathrm{x} /$ day, 28 days & Very weak ${ }^{49}$ \\
\hline
\end{tabular}




\section{Local x Systemic}

Few comparative studies have assessed which administration route of the chemical adjuncts would lead to better clinical results in AP treatment.

Purucker et al. ${ }^{48}$ analyzed the effectiveness of association between tetracycline impregnated fibers (local) and amoxicillin + clavulanic acid (systemic) administered 3 months after SRP in AP treatment. The results indicate similar clinical parameters after 9 months of observation period. As previously reported, the best results seem to be obtained with systemic antibiotic administration in conjunction with or immediately after conventional therapy ${ }^{45}$.

Another study compared the use of chlorhexidine chip (local) and amoxicillin + metronidazole (systemic) as adjuncts to conventional therapy in patients with AP. The association with systemic antibiotics has been shown more effective in clinical measures rehabilitation ${ }^{49}$.

In the light of the small number of participants of this comparative analysis studies makes it difficult to establish a proper conclusion.

\section{DISCUSSION}

When it analyzes the auxiliary local therapies, most studies demonstrate an additional effect in CAL gain when using the chlorhexidine chip in the chronic periodontitis treatment. Although Duarte et al. ${ }^{30}$ found favorable clinical outcomes with the chlorhexidine chip use, there are no studies or consistent evidence that recommend its indication for the AP treatment.

In the case of antibiotics administered locally, the literature also presents few studies for the AP treatment. The pilot study of A囚an et al. ${ }^{31}$ involved patients with chronic and aggressive periodontitis and no statistically significant differences were found between the groups. Therefore, also for the local antibiotics, at the present moment there is no scientific evidence to justify its use in the AP treatment. Further studies with standardized methodologies are needed to determine any additional benefit of this protocol type.

Recently, two papers found favorable results as the use of PDT in the AP treatment ${ }^{33-34}$. Nevertheless, further studies are needed to prove the real importance of this therapy.
In relation to systemic adjuvants literature shows a large number of studies. In this context, antibiotics are the most researched drugs. Most studies point to a further clinical effect when antibiotics are part of the AP treatment protocol. In addition, the association of these antimicrobial drugs seems to be the current focus of research. As in the case of amoxicillin + metronidazole, good results presented are due to wide spectrum of action provided. Metronidazole affects specifically the anaerobic oral flora, including P. gingivalis, T. forsythia and $T$. denticola, microorganisms attached to the red Socransky's complex ${ }^{50}$, while $A$. actinomycetemcomitans, an optional anaerobic bacterium, appears to be widely opposed by the amoxicillin ${ }^{38-39,41 .}$

The anti-inflammatory effect in the AP treatment was not observed. In addition, the studies with these drugs have inconsistent data and, therefore, do not allow any indication ${ }^{46-47}$.

\section{FINAL CONSIDERATIONS}

The local chemical adjuvants are quite used in the chronic periodontitis treatment in refractory or recurrent sites. However, his indication in the AP treatment needs to be better understood.

Although most studies show benefits in the conventional treatment and systemic antibiotics, it may be impossible to advocate a single protocol for all cases of AP. Susceptibility factors; pathogenesis and subgingival micro flora do not appear to be identical to all patients affected by this disease form. The biggest challenge in the diagnosis and treatment of these patients may be in individual risk analysis that should include microbiological tests for recognition of subgingival micro flora to indicate a specific treatment protocol, since these changes seem to be specific.

\section{Callaborators}

LG AYUB participated in the design, structuring and article writing. AB NOVAES JUNIOR, MFM GRISI, SLS SOUZA and DB PALIOTO participated in the design, review and article writing. M TABA JUNIOR was responsible for guidance, development and article writing. 


\section{REFERÊNCES}

1. Lang NP, Bartold PM, Cullinam M, Jeffcoat M, Mombelli $A$, Murakami S, et al. International Classification Workshop. Consensus report: Aggressive periodontitis. Ann Periodontol. 1999;4(1):53.

2. Tonetti M, Mombelli A. Early onset periodontits. Ann Periodontol 1999;4(1):39-53.

3. Walker CB, Gordon JM, Magnusson I, Clark WB. A role of antibiotics in the treatment of refractory periodontitis. J Periodontol. 1993;64(8 Suppl):772-81. doi:10.1902/jop.1993.64.8s.772

4. Haffajee AD, Dibart S, Kent RL Jr, Socransky SS. Factors associated with different responses to periodontal therapy. J Clin Periodontol. 1995;22(8):628-36. doi: 10.1111/j.1600051X.1995.tb00816.x

5. Renvert S, Wikström M, Dahlén G, Slots J, Egelberg J. On the inability of root debridement and periodontal surgery to eliminate Actinobacillus actinomycetemcomitans from periodontal pockets. J Clin Periodontol 1990;17(6):351-5. doi: 10.1111/j.1600-051X.1990.tb00030.x

6. van Winkelhoff AJ, Rams TE, Slots J. Systemic antibiotic therapy in periodontics. Periodontol 2000 1996;10(1):45-78. doi: 10.1111/j.1600-0757.1996.tb00068.x

7. Hanes PJ, Purvis JP. Local anti-infective therapy: pharmacological agents. A systematic review. Ann Periodontol. 2003;8(1):79-98.

8. Haffajee AD, Socransky SS, Gunsolley JC. Systemic anti-infective periodontal therapy: a systematic review. Ann Periodontol. 2003;8(1):115-81.

9. Herrera D, Sanz M, Jepsen S, Needleman I, Roldán S. A systematic review on the effect of systemic antimicrobials as an adjunctive to scaling and root planning in periodontitis patients. J Clin Periodontol. 2002;29(3 Suppl):136-59.

10. Kirkwood KL, Taba Jr M, Rossa C, Giannobile WV. Comparison of pathology of periodontal disease and rheumatoid arthritis. In: Newman MG, Takei H, Carranza FA, Klokkevold YJ. Carranza's clinical periodontology. 10 ${ }^{\text {th }}$ ed. St. Louis: Elsevier; 2006.

11. Kornman KS. Host modulation as a therapeutic strategy in the treatment of periodontal disease. Clin Infect Dis. 1999;28(3):520-6.

12. Addy M. Chlorexidine compared with other locally delivered antimicrobials. A short review. J Clin Periodontol. 1986;13(10):957-64.

13. Mandell RL, Socransky SS. Microbiological and clinical effects of surgery plus doxycycline on juvenile periodontitis. J Periodontol 1988;59(6):373-9. doi: 10.1902/jop.1988.59.6.373

14. Löe $H$, Schiott CR. The effect of mouthrinses and topical application of chlorhexidine on the development of dental plaque and gingivitis in man. J Periodontal Res 1970;5(2):79-83. doi: 10.1111/j.1600-0765.1970.tb00696.x

15. Wade WG, Addy M. In vitro activity of a chlorhexidine containing mouthwash against subgingival bacteria. J Periodontol. 1989;60(9):521-5. doi: 10.1902/jop.1989.60.9.521

16. Watts EA, Newman HN. Clinical effects on chronic periodontitis of a simplified system of oral hygiene including subgingival pulsated jet irrigation with chlorhexidine. J Clin Periodontol. 1986;13(7):666-70.

17. Wennström JL, Heijl L, Dahlén G, Gröndahl K. Periodic subgingival antimicrobial irrigation of periodontal pockets (I) Clinical observations. J Clin Periodontol 1987;14(9):541-50.

18. Jolkovsky DL, Waki MY, Newman MG, Otomo-Corgel J, Madison M, Flemmig TF, et al. Clinical and microbiological effects of subgingival and gingival irrigation with chlorhexidine gluconate. J Periodontol. 1990;61(11):663-9. doi:10.1902/ jop.1990.61.11.663

19. Tseng PW, Newcomb GM. The effect of a single episode of irrigation on the gingival response to scaling and root planing. J Clin Dent. 1991;2(4):83-6.

20. Krust KS, Drisko CL, Gross K, Overman P, Tira DE. The effects of subgingival irrigation with chlorhexidine and stannous fluoride: a preliminary investigation. J Dent Hyg. 1991;65(6):289-95.

21. Chapple IL, Walmsley AD, Saxby MS, Moscrop H. Effect of subgingival irrigation with chlorexidine during ultrasonic scaling. J Periodontol. 1992;63(10):812-6.

22. Guarnelli ME, Franceschetti G, Manfrini R, Trombelli L. Adjunctive effect of ultrasonic instrumentation of aggressive periodontitis patients: a pilot study. J Clin Periodontol. 2008;35(4):333-41. doi: 10.1111/j.1600-051X.2008.01199.x

23. Mongardini C, van Steenberghe D, Dekeyser C, Quirynen M. One stage full-versus partial-mouth disinfection in the treatment of chronic adult or generalized early-onset periodontitis. I. Longterm clinical observations. J Periodontol. 1999;70(6):632-45. doi:10.1902/jop.1999.70.6.632

24. Quirynen M, Mongardini C, Pauwels $M$, Bollen CML, van Eldere J, van Steenberghe D. One stage full- versus partial-mouth disinfection in the treatment of chronic adult and generalized early-onset periodontits. II. Long-term impact on microbial load. J Periodontol 1999;70(6):646-56. doi:10.1902/jop.1999.70.6.646

25. Lang NP, Tan WC, Krähenmann MA, Zwahlen M. A systematic review of the effects of full-mouth debridement with and without antiseptics in patients with chronic periodontitis. J Clin Periodontol. 2008;35(8 Suppl):8-21. doi: 10.1111/j.1600051X.2008.01257.x

26. Soskolne WA, Heasman PA, Stabhloz A, Smart GJ, Palmer M, Flashner $\mathrm{M}$, et al. Susteined local delivery of chlorhexidine in the treatment of periodontits: a multi-center study. J Periodontol. 1997;68(1):32-8. doi: 10.1902/jop.1997.68.1.32

27. Jeffcoat MK, Bray KS, Ciancio SG, Dentino AR, Fine $D H$, Gordon JM, et al. Adjunctive use of subgingival controlledrelease chlorhexidine chip reduces probing depth and improves attachment level compared with scaling and root planning alone. J Periodontol. 1998;69(7):989-97. doi: 10.1902/ jop.1998.69.9.989

28. Azmak N, Atilla G, Louto H, Sorsa T. The effect of controlledreleased delivery of chlorexidine chip on clinical parameters and matrix metalloproteinase -8 levels in gingival crevicular fluid. J Periodontol 2002;73(6):608-15.

29. Grisi DC, Salvador SL, Figueiredo LC, Souza SLS, Novaes Jr AB Grisi MFM. Effect of controlled-released chlorexidine chip on clinical and microbiological parameters of periodontal syndrome. 
J Clin Periodontol. 2002;29(10):875-81. doi: 10.1034/j.1600051X.2002.291001.x

30. Duarte FF, Lotufo RF, Pannuti CM. Local delivery of chlorexidine gluconate in patients with aggressive periodontitis. J Int Acad Periodontol. 2008;10(1):31-5.

31. A囚an S, Sönmez S, Serdar M. The effect of topical doxycycline usage on gingival crevicular fluid MMP-8 levels of chronic and aggressive periodontitis patients: a pilot study. Int J Dent Hyg. 2006;4(3):114-21. doi: 10.1111/j.1601-5037.2006.00174.x

32. Kömerick N, Nakanishi H, MacRobert AG, Henderson B, Speight $\mathrm{P}$, Wilson $\mathrm{M}$. In vivo killing of Porphyromonas gingivalis by toluidine blue-mediated photosensibilization in an animal model. Antimicrob Agents Chemother. 2003;47(3):932-40. doi: 10.1128/AAC.47.3.932-940.2003

33. de Oliveira RR, Schwartz-Filho HO, Novaes Jr AB, Taba Jr $M$. Antimicrobial photodynamic therapy in the non-surgical treatment of aggressive periodontitis: a preliminary randomized controlled clinical study. J Periodontol. 2007;78(6):965-73. doi:10.1902/jop.2007.060494

34. de Oliveira RR, Schwartz-Filho HO, Novaes Jr AB, Garlet GP, de Souza RF, Taba Jr M, de Souza SLS, Ribeiro FJ. Antimicrobial photodynamic therapy in the non-surgical treatment of aggressive periodontitis: cytokine profile in gingival crevicular fluid, preliminary results. J Periodontol. 2009;80(1):98-105. doi: 10.1902/jop.2009.070465

35. Azarpazhooh A, Shah PS, Tenenbaum HC, Goldberg MB. The effect of photodynamic therapy for periodontitis: a systematic review and meta-analysis. J Periodontol. 2010;81(1):4-14. doi: 10.1902/jop.2009.090285

36. Guerrero A, Griffiths GS, Nibali L, Suvan J, Moles DR, Laurell L, et al. Adjunctive benefits of systemic amoxicillin and metronidazole in non-surgical treatment of generalized aggressive periodontitis: a randomized placebo-controlled clinical trial. J Clin Periodontol. 2005;32(10):1096-107. doi: 10.1111/j.1600051X.2005.00814.x

37. Valenza G, Veihelmann S, Perplies J, Tichy D, RoldanPareja M del C, Schlagenhauf $U$, et al. Microbial changes in periodontits successfully by mechanical plaque removal and systemic amoxicillin and metronidazole. Int J Med Microbiol. 2009;299(6):427-38. doi: 10.1016/j.ijmm.2009.03.001

38. Mestnik MJ, Feres M, Figueiredo LC, Duarte PM, Lira EAG, Faveri $M$. Short-term benefits of the adjunctive use of metronidazole plus amoxicillin in the microbial profile and in the clinical parameters of subjects with generalized aggressive periodontitis. J Clin Periodontol. 2010;37(4):353-65. doi: 10.1111/j.1600051X.2010.01538.x

39. Yek EC, Cintan S, Tpocuoglu N, Kulekci G, 凶ssever H, Kantarci A. Efficacy of amoxicillin and metronidazole combination for the management of generalized aggressive periodontitis. J Periodontol. 2010;81(7):964-74. doi: 10.1902/jop.2010.090522

40. Akincibay $H$, Orsal SO, Sengün $D$, Tözüm TF. Sistemic administration of doxycycline versus metronidazol plus amoxicillin in the treatment of localized aggressive periodontitis: a clinical and microbiologic study. Quintessence Int. 2008;39(2):33-9.

41. Xajigeorgiou C, Sakellari D, Slini T, Baka A, Konstantinidis A. Clinical and microbiological effects of different antimicrobials on generalized aggressive periodontitis. J Clin Periodontol. 2006;33(4):254-64. doi: 10.1111/j.1600-051X.2006.00905.x

42. Machtei $E E$, Younis $M N$. The use of 2 antibiotic regimens in aggressive periodontitis: comparison of changes in clinical parameters and gingival crevicular fluid biomarkers. Quintessence Int 2008;39(10):811-9.

43. Haas AN, de Castro GD, Moreno T, Susin C, Albandar JM, Oppermann RV, et al. Azithomycin as an adjunctive treatment of aggressive periodontitis: 12-months randomized clinical trial. J Clin Periodontol 2008;35(8):696-704. doi: 10.1111/j.1600051X.2008.01254.x

44. Guerrero A, Echeverría JJ, Tonetti MS. Incomplete adherence to na adjunctive systemic antibiotic regimen decreases clinical outcomes in generalized aggressive periodontitis patients: a pilot retrospective study. J Clin Periodontol. 2007;34(10):897902. doi: 10.1111/j.1600-051X.2007.01130.x

45. Kaner D, Christan C, Dietrich T, Bernimoulin J-P, Kleber B-M, Friedmann A. Timing affects the clinical outcome of adjunctive systemic antiotic therapy for generalized aggressive periodontitis. J Periodontol. 2007a;78(7):1201-8. doi:10.1902/ jop.2007.060437

46. Azoubel MCF, Sarmento VA, Cangussú V, Azoubel E, Bittencourt $S$, Cunha FQ, Ribeiro RA, et al. Adjunctive benefits of systemic etoricoxib in non-surgical treatment of aggressive periodontitis: short-term evaluation. J Periodontol 2008;79(9):1719-25.

47. Pinho MN, Pereira LB, de Souza SLS, Palioto DB, Grisi MFM, Novaes Jr AB, Taba Jr M. Short-term effect of COX-2 selector inhibitor as an adjunctive for the treatment of periodontal disease - A clinical double-blind study in humans. Braz Dent J 2008;19(4):323-8.

48. Purucker P, Mertes H, Goodson JM, Bernimoulin J-P. Local versus systemic adjunctive antibiotic therapy in 28 patients with generalized aggressive periodontitis. J Periodontol 2001;72(9):1241-5.

49. Kaner D, Bernimoulin J-P, Hopfenmüller W, Kleber B-M, Friedmann A. Controlled-delivery chlorhexidine chip versus amoxicillin / metronidazole as adjunctive antimicrobial therapy for generalized aggressive periodontitis: a randomized controlled clinical trial. J Clin Periodontol. 2007b;34(10):880-91. doi: 10.1902/jop.2007.060437

50. Socransky SS, Haffajee AD, Cugini MA, Smith C, Kent RL Jr. Microbial complexes in subgingival plaque. J Clin Periodontol. 1998;25(2):134-44. doi: 10.1111/j.1600-051X.1998.tb02419.x

Received on: 18/8/2010

Final version resubmitted on: 16/3/2011

Approved on: 15/6/2011 